\title{
BMJ Open Early respiratory diagnosis: benefits of Respiratory Research enhanced lung function assessment
}

\author{
Karl P Sylvester, ${ }^{1,2}$ Luke Youngs (1) , ${ }^{3}$ M A Rutter, ${ }^{4}$ Ross Beech, ${ }^{4}$ Ravi Mahadeva ${ }^{5}$
}

To cite: Sylvester KP, Youngs L, Rutter MA, et al. Early respiratory diagnosis: benefits of enhanced lung function assessment. BMJ Open Resp Res 2021;8:e001012. doi:10.1136/ bmjresp-2021-001012

Received 8 June 2021 Accepted 27 June 2021

\section{Check for updates}

(c) Author(s) (or their employer(s)) 2021. Re-use permitted under CC BY-NC. No commercial re-use. See rights and permissions. Published by BMJ.

${ }^{1}$ Respiratory Physiology, Papworth Hospital NHS Foundation Trust, Cambridge, UK

${ }^{2}$ Cambridge University Hospitals NHS Foundation Trust, Cambridge, UK ${ }^{3}$ Lung Function Department, East Sussex Healthcare NHS Trust, Saint Leonards-on-Sea, UK

${ }^{4}$ Lung Function Unit, Cambridge University Hospitals NHS Foundation Trust, Cambridge, UK ${ }^{5}$ COPD Centre, Cambridge University Hospitals NHS Foundation Trust, Cambridge, UK

Correspondence to Dr Karl P Sylvester; karl.sylvester@nhs.net

\section{ABSTRACT}

Introduction The National Health Service for England Long Term Plan identifies respiratory disease as one of its priority workstreams. To assist with earlier and more accurate diagnosis of lung disease they recommend improvement in delivery of quality-assured spirometry. However, there is a likelihood that patients will present with abnormal gas exchange when spirometry results are normal and therefore there will be a proportion of patients whose time to diagnosis is still protracted. We wished to determine the incidence rate of this occurring within our Trust.

Methods A retrospective review of all patients attending the lung function laboratory for their first pulmonary function assessment from June 2006 to December 2020 was undertaken. Forced expiratory volume in $1 \mathrm{~s} /$ forced vital capacity $(\mathrm{FEV} / \mathrm{FVC})>-1.64$ standardised residual (SR) was used to confirm no obstructive lung function abnormality and FVC $>-1.64$ SR to confirm no suggestion of a restrictive lung function abnormality. Lung gas transfer for carbon monoxide (TLCO) and transfer coefficient of the lung for carbon monoxide $(\mathrm{KCO})<-1.64 \mathrm{SR}$ confirmed the presence of a gas exchange abnormality. Spirometry and gas transfer reference values generated by the Global Lung Initiative were used to determine normality.

Results of 12835 eligible first visits with normal $\mathrm{FEV}_{1} /$ FVC and FVC, 4856 (37.8\%) were identified as having an abnormally low TLCO and 3302 (25.7\%) presenting with an abnormally low KCO. Of 3494 with $\mathrm{FEV}_{1} / \mathrm{FVC} \mathrm{SR}<-1.64$, 3316 also had a ratio of $<0.70$, meaning $178(5 \%)$ of patients in this cohort would have been misclassified as having obstructive lung disease using the 0.70 cutoff recommended by the Global Initiative for Chronic Obstructive Lung Disease for diagnosing obstructive lung disease.

Discussion In conclusion, to assist with ensuring more accurate and timely diagnosis of lung disease and enhance patients' diagnostic pathway, we recommend the performance of lung gas transfer measurements alongside spirometry in all healthcare settings. To assess and monitor gas transfer at the earliest opportunity we recommend this is implemented into new models being developed within community hubs. This will increase the identification of lung function abnormalities and provide patients with a definitive diagnosis earlier.

\section{BACKGROUND}

Respiratory disease is the third biggest cause of death in the UK and affects one in five people in England, with no improvement in respiratory disease mortality rates for over

\section{Key messages}

Spirometry alone does not help to identify all respiratory diagnoses earlier.

- Enhanced lung function testing will assist in identifying patients with respiratory abnormalities that spirometry alone misses.

We demonstrate why enhanced lung function testing is important and the proportion of patients this will benefit.

10 years. ${ }^{1}$ In light of this and for the first time, the National Health Service in England (NHSE) has designated respiratory disease as a clinical priority as part of its Long Term Plan. The plan highlights the importance of reaching an earlier and more accurate diagnosis as an objective. ${ }^{2}$ To address the shortfalls surrounding time and accuracy of diagnosis, the NHSE Long Term Plan advocates the performance of quality-assured spirometry in the community.

Spirometry is the most common pulmonary function test undertaken and is used worldwide as the first-line diagnostic tool in the primary care setting when attempting to identify lung disease. ${ }^{34}$ It is an effective procedure for differentiating obstructive from other lung function abnormalities. ${ }^{5}$ The use of quality-assured spirometry is recommended frequently in national and international guidelines for the diagnosis and management of asthma and chronic obstructive pulmonary disease (COPD) both in primary and secondary care ${ }^{6-8}$ However, the ability of the respiratory system to exchange gases to and from the cardiovascular system can be impaired despite the presence of normal spirometry. ${ }^{9}$ Anecdotally, we were aware of patients presenting with normal spirometry results and yet abnormal gas exchange as measured by the single breath technique. We believe it is important to understand the impact measuring gas transfer might have on our ability to diagnose lung disease that spirometry alone might miss. This would clearly have the potential to influence future 
strategy on the ability to identify lung disease earlier. Due to alterations in the alveolar-capillary membrane and lung vasculature, the lung diseases that this would impact would include pulmonary vascular disorders, early interstitial lung disease or early emphysema. ${ }^{9}$

Our aim was to investigate what proportion of patients attending our department for their first diagnostic assessment presented with normal spirometry yet abnormal gas transfer. This will impact time to first diagnoses, resulting in a continued protracted pathway and reducing the ability to detect lung disease at the earliest opportunity.

\section{METHODS}

A retrospective review of all patients referred to Cambridge University Hospitals' lung function department for their first diagnostic assessment from June 2006 to December 2020 was undertaken. Spirometry and single breath gas transfer were performed to European Respiratory Society (ERS)/American Thoracic Society (ATS) standards. ${ }^{10}$ Global Lung Initiative (GLI) ${ }^{12}$ reference equations were used to determine normality. Forced expiratory volume in $1 \mathrm{~s}$ /forced vital capacity $\left(\mathrm{FEV}_{1} / \mathrm{FVC}\right)>-1.64$ standardised residual (SR) was used to confirm no obstructive lung function abnormality and FVC $>-1.64$ SR to confirm no suggestion of a restrictive lung function abnormality. Lung gas transfer for carbon monoxide (TLCO) and transfer coefficient of the lung for carbon monoxide $(\mathrm{KCO})<-1.64 \mathrm{SR}$ confirmed the presence of a gas exchange abnormality.

Due to the limits of the GLI reference data set, gas transfer data had to be excluded for all non-Caucasian patients and those older than 85 years of age.

\section{Patient and public involvement}

This analysis was based on anonymised retrospective data from historical lung function results.

\section{RESULTS}

Of 27856 first visits, data from 1224 non-Caucasian patients and 638 patients older than 85 years of age had to be excluded (figure 1).

Of 25994 subsequent first visits, 8816 had missing single breath gas transfer data. Of these 3494 were identified as having an abnormal $\mathrm{FEV}_{1} / \mathrm{FVC}$ and 849 as having an abnormal FVC. Of the 3494 with $\mathrm{FEV}_{1} / \mathrm{FVC}$ $\mathrm{SR}<-1.64,3316$ also had a ratio of $<0.70$, meaning 178 $(5 \%)$ of patients in this cohort would have been misclassified as having obstructive lung disease using the 0.70 cutoff recommended by the Global Initiative for Chronic Obstructive Lung Disease for diagnosing obstructive lung disease.

Of the remaining 12835 results, $4856 \quad(37.8 \%)$ presented with an abnormally low TLCO and 3302 (25.7\%) presenting with an abnormally low KCO. Information on this group is found in table 1 .

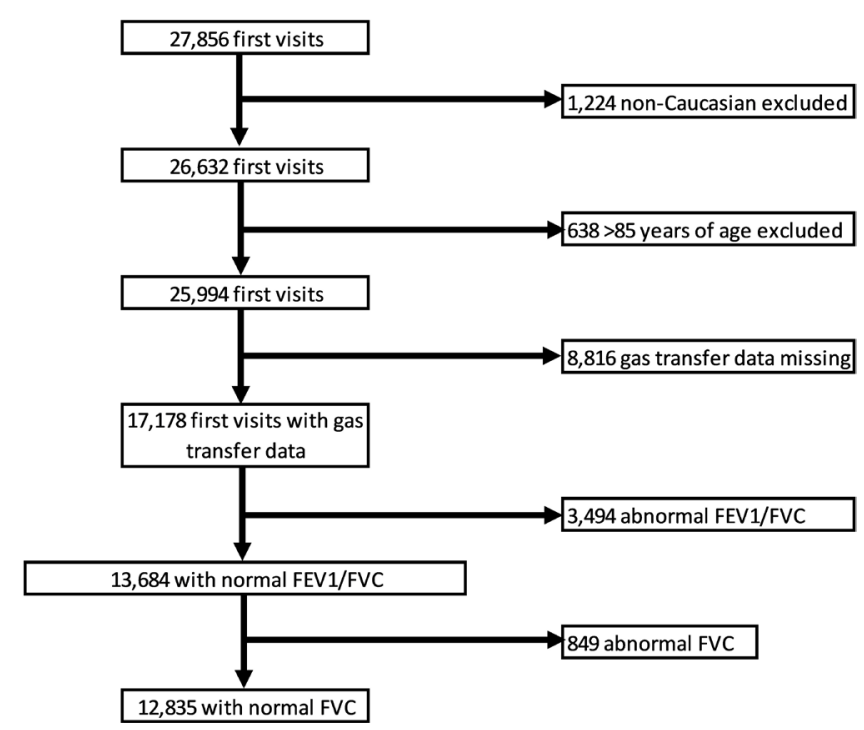

Figure 1 A flow diagram demonstrating the number of patients included in each step of the analysis. FEV , forced expiratory volume in $1 \mathrm{~s}$; FVC, forced vital capacity.

Of 4856 with an abnormal TLCO, 3040 also had an abnormal KCO. Of 4856 patients 2029 had an abnormal Alveolar Volume (VA). Of the patients 937 had an abnormal TLCO, KCO and VA combined. Of the 262 with an isolated low KCO, 45 also had an elevated VA and the remainder all had normal VA. Information on this group is found in table 2

\section{DISCUSSION}

We have demonstrated that a proportion of patients referred to secondary care for their first respiratory diagnostic assessment present with normal spirometry yet abnormal gas transfer. These results have implications when solely using spirometry in order to detect respiratory function abnormalities earlier and could ultimately result in a continued protraction of patient diagnosis. These results support the proposed diagnostic pathway for patients presenting with breathlessness to

Table 1 Demographic information of first visit patients with normal spirometry

\begin{tabular}{lll}
\hline Male:female & $6520: 6315$ & \\
\hline & Mean & SD \\
\hline Age (years) & 61.0 & 16.1 \\
FEV ${ }_{1}$ SR & 0.92 & 1.24 \\
FVC SR FEV $_{1} /$ FVC SR & 1.40 & 1.40 \\
TLCOc SR $_{\text {KCOc SR }}$ & 0.11 & 0.76 \\
\hline
\end{tabular}

Lung function results are presented as standardised residual (SR). $\mathrm{FEV}_{1}$, forced expiratory volume in $1 \mathrm{~s}$; FVC, forced vital capacity; $\mathrm{KCOc}$, transfer coefficient of the lung for carbon monoxide corrected; TLCOc, transfer for carbon monoxide corrected. 
Table 2 Demographic information of first visit patients with normal spirometry but abnormal gas transfer

\begin{tabular}{lcc}
\hline Male:female & $2809: 2047$ & \\
\hline & Mean & SD \\
\hline Age (years) & 67.1 & 13.2 \\
FEV 1 SR & 1.18 & 1.23 \\
FVC SR & 1.72 & 1.40 \\
FEV $/$ FVC SR & 0.32 & 0.64 \\
TLCOc SR & -3.12 & 1.24 \\
KCOc SR & -2.14 & 1.28 \\
\hline
\end{tabular}

Lung function results are presented as standardised residual (SR). $\mathrm{FEV}_{1}$, forced expiratory volume in $1 \mathrm{~s}$; FVC, forced vital capacity; $\mathrm{KCOc}$, transfer coefficient of the lung for carbon monoxide corrected; TLCOc, transfer for carbon monoxide corrected.

a community practitioner suggested by the Taskforce for Lung Health, with the latest pathway including the performance of single breath gas transfer earlier within the patient's diagnostic journey.

Within the NHSE Long Term Plan $^{2}$ and the subsequent Richard's review, ${ }^{13}$ there is emphasis on the National Health Service to do more to detect and diagnose respiratory problems earlier and within a community setting. Performance of spirometry and improving the quality of assessment are highlighted as methods to achieve this aim within the NHSE Long Term Plan, particularly with regard to diagnosing COPD. Spirometry is clearly a key assessment to assist in providing a differential diagnosis of respiratory disease and is thought to be a relatively simple test to undertake. Recent equipment innovation means that ambulatory equipment is now available for the performance of gas transfer as well as spirometry. In addition, the performance of gas transfer is no less arduous than that of spirometry. However, consideration would need to be given to appropriate training and competency of healthcare professionals performing gas transfer. Training and certification on the performance of quality-assured spirometry are well established and provided by the Association for Respiratory Technology and Physiology. Consideration would need to be given regarding the training of healthcare professionals in addition to spirometry or whether addition of this test warrants greater input from those already trained in its performance, for example, physiologists. Currently the healthcare professionals that are appropriately trained in the performance of this measurement are healthcare scientists. Their advanced skills in the performance of gas transfer and other more advanced respiratory physiological assessments would greatly assist in the earlier and more accurate diagnosis of lung disease in a community setting, for example, in community diagnostic hubs that are currently being established nationwide.

The importance of measuring diffusive capacity is also evident in the identification, monitoring and recovery of patients during the post-COVID-19 phase. Evidence in discharged COVID-19 survivors suggests impairment of diffusion capacity is the most common abnormality of lung function and is associated with severity of the disease, whereas even in the most severe cases spirometry values largely remained within a normal range. ${ }^{14} 15$ Furthermore, $52.6 \%$ of patients who performed pulmonary function testing 30 days post-COVID-19 recovery presented with abnormal diffusion capacity. ${ }^{16}$ The British Thoracic Society guidance regarding respiratory follow-up in patients with COVID-19 highlights the importance of performing lung function testing and suggests the performance of full lung function tests 12 weeks after discharge in those who were cared for in high-dependency or intensive care units. ${ }^{17}$

Of course our results also mean that there were a significant proportion of patients in whom both spirometry and gas transfer were normal. In our current pathway patients are referred to the hospital with or without community spirometry having been performed. On occasions when spirometry has been performed it is not always to a quality-assured standard and means a doubling-up on diagnostic procedures. The patient is then placed on an 18-week referral to treat pathway. They will wait to see a clinician, wait again for diagnostic procedures and then wait again to return to see the clinician. Therefore our results demonstrate that there is an extra unnecessary burden on the healthcare system when diagnostic results come back normal. With the availability of these results much earlier in the patient pathway, the likelihood is that these patients would not have subsequently required a referral to secondary care for review and could have been managed within primary care. This then has implications in terms of the number of referrals required to secondary and tertiary care, which would likely decline. This reduces waiting times into secondary care, allowing patients with more complex disease to be seen earlier. There will also be savings within the overall healthcare economy and patient benefits through the following:

1. Ensuring patients receive a diagnosis early without the need to continue to return with ongoing symptoms suggestive of respiratory disease and the potential for unnecessary trials of medication prescriptions to try and alleviate ongoing symptoms, which will reduce costs of medications.

2. A reduction in unnecessary referrals: every referral from the community to secondary or tertiary care attracts a fee, such as Treatment Function Code 340 Respiratory Medicine, which for a first attendance is $£ 221$. By undertaking appropriate diagnostics tests earlier in the pathway we could identify those patients who do not need to be referred further and thus saving this cost per patient as a minimum.

3. A reduction in non-essential diagnostic procedures: this ties in with point 1 above, but referral to secondary/tertiary care may also attract further unnecessary diagnostic assessments such as CT, which does not only result in a cost but also exposure to unnecessary radiation. 
4. A reduction in the number of consultations to the primary care practice with ongoing symptoms, freeing up time and space for the practice to handle calls and requests from more patients.

We have demonstrated that $5 \%$ of patients within our cohort would have been misclassified as having an obstructive pattern to their lung function by using a fixed ratio of 0.7 compared with the use of lower limits of normal (LLN) or SRs. The merits of using LLN and SRs have been well described elsewhere, ${ }^{18}$ and we would encourage readers to familiarise themselves with the utility of these parameters in comparison with fixed cut-offs.

There is a potential for bias in our sample. This retrospectively sampled cohort of patients were those who were referred to the Trust and then subsequently requested lung function assessments. It is likely that there were a proportion of patients seen within the thoracic medicine clinic that were managed by the clinical team without the need for lung function. This is only a snapshot in time. None of the patients was preselected for analysis; these were all comers that met the inclusion criteria and it appropriately reflects our practice. Another limitation to this study is that we do not know what happened to the patients in primary care for the equivalent period in terms of their diagnostic assessment and management. We also did not directly assess whether a normal spirometry result in the community prevented a referral to secondary care. Clearly there are implications to patient diagnosis, management and ongoing care should a normal spirometry result in a patient with abnormal gas transfer not result in a secondary care referral. Specialist input into community diagnosis from trained healthcare professionals in respiratory diagnostic assessments would help to triage patients to the most appropriate pathway.

In conclusion, we recommend the performance of lung gas transfer alongside spirometry at the earliest opportunity within a patient's diagnostic pathway. This will ensure more accurate and timely diagnosis of lung abnormalities associated with respiratory disease, with earlier detection of significant disease being enhanced by this approach. To assess and monitor gas transfer at the earliest opportunity we recommend this is implemented into new models being developed within community hubs. This will likely increase the identification of lung function abnormalities and provide patients with a definitive diagnosis earlier.

Contributors Study design: KPS. Data collection: KPS, MAR, LY, RB. Data analysis: KPS, MAR. Draft manuscript: KPS, LY, RB. Manuscript review: KPS, MAR, LY, RB, RM.

Funding The authors have not declared a specific grant for this research from any funding agency in the public, commercial or not-for-profit sectors.

Competing interests None declared.

Patient and public involvement Patients and/or the public were not involved in the design, or conduct, or reporting, or dissemination plans of this research.

Patient consent for publication Not required.
Ethics approval The study was approved by the Cambridge University Hospitals NHS Foundation Trust Research and Development Board (ref: PRN8450).

Provenance and peer review Not commissioned; externally peer reviewed.

Data availability statement № data are available.

Open access This is an open access article distributed in accordance with the Creative Commons Attribution Non Commercial (CC BY-NC 4.0) license, which permits others to distribute, remix, adapt, build upon this work non-commercially, and license their derivative works on different terms, provided the original work is properly cited, appropriate credit is given, any changes made indicated, and the use is non-commercial. See: http://creativecommons.org/licenses/by-nc/4.0/.

ORCID iD

Luke Youngs http://orcid.org/0000-0002-6587-5559

\section{REFERENCES}

1 The Battle for Breath - the impact of lung disease in the UK, 2016. Available: https://www.blf.org.uk/policy/the-battle-for-breath-2016

2 The NHS long term plan 2019. Available: https://www.longtermplan. nhs.uk/wp-content/uploads/2019/08/nhs-long-term-plan-version-1. 2.pdf

3 Graham BL, Steenbruggen I, Miller MR, et al. Standardization of spirometry 2019 update. An official American thoracic Society and European respiratory Society technical statement. Am J Respir Crit Care Med 2019;200:e70-88.

4 Derom E, van Weel C, Liistro G, et al. Primary care spirometry. Eur Respir J 2008;31:197-203.

5 Levy ML, Quanjer PH, Booker R, et al. Diagnostic spirometry in primary care: Proposed standards for general practice compliant with American Thoracic Society and European Respiratory Society recommendations: a General Practice Airways Group (GPIAG)1 document, in association with the Association for Respiratory Technology \& Physiology (ARTP)2 and Education for Health3 1 www. gpiag.org 2 www.artp.org 3 www.educationforhealth.org.uk. Prim Care Respir J 2009;18:130-47.

62020 global strategy for prevention, diagnosis and management of COPD, 2020. Available: https://goldcopd.org/wp-content/uploads/ 2019/12/GOLD-2020-FINAL-ver1.2-03Dec19_WMV.pdf

7 Global strategy for asthma management and prevention, 2019. Available: https://ginasthma.org/wp-content/uploads/2019/06/GINA2019-main-report-June-2019-wms.pdf

8 Asthma: diagnosis, monitoring and chronic asthma management, 2017. Available: https://www.nice.org.uk/guidance/ng80/resources/ asthma-diagnosis-monitoring-and-chronic-asthma-managementpdf-1837687975621

9 Pellegrino R, Viegi G, Brusasco V, et al. Interpretative strategies for lung function tests. Eur Respir J 2005;26:948-68.

10 Miller MR, Hankinson J, Brusasco V, et al. Standardisation of spirometry. Eur Respir J 2005;26:319-38.

11 Macintyre N, Crapo RO, Viegi G, et al. Standardisation of the singlebreath determination of carbon monoxide uptake in the lung. Eur Respir J 2005;26:720-35.

12 Quanjer PH, Stanojevic S, Cole TJ, et al. Multi-ethnic reference values for spirometry for the 3-95-yr age range: the global lung function 2012 equations. Eur Respir J 2012;40:1324-43.

13 Diagnostics: recovery and renewal: report of the independent review of diagnostic services for NHS England, 2020. Available: https:// www.england.nhs.uk/wp-content/uploads/2020/11/diagnosticsrecovery-and-renewal-independent-review-of-diagnostic-servicesfor-nhs-england-2.pdf

14 Huang Y, Tan C, Wu J, et al. Impact of coronavirus disease 2019 on pulmonary function in early convalescence phase. Respir Res 2020;21:163.

15 Zhao Y-M, Shang Y-M, Song W-B, et al. Follow-up study of the pulmonary function and related physiological characteristics of COVID-19 survivors three months after recovery. EClinicalMedicine 2020;25:100463.

16 Mo X, Jian W, Su Z, et al. Abnormal pulmonary function in COVID-19 patients at time of hospital discharge. Eur Respir J 2020;55. doi:10.1183/13993003.01217-2020. [Epub ahead of print: 1806 2020].

17 George PM, Barratt SL, Condliffe R, et al. Respiratory follow-up of patients with COVID-19 pneumonia. Thorax 2020;75:1009-16.

18 Miller MR, Quanjer PH, Swanney MP, et al. Interpreting lung function data using $80 \%$ predicted and fixed thresholds misclassifies more than $20 \%$ of patients. Chest 2011;139:52-9. 